\title{
Discrete and continuous approach in the conceptualization of psychoses Cyril Hoschl
}

\author{
Address: Prague Psychiatric Centre \& 3rd Medical Faculty, Charles University, Prague, Czech Republic \\ from International Society on Brain and Behaviour: 3rd International Congress on Brain and Behaviour \\ Thessaloniki, Greece. 28 November - 2 December 2007 \\ Published: 17 April 2008 \\ Annals of General Psychiatry 2008, 7(Suppl I):S4I doi:I0.II86/I744-859X-7-SI-S4 I
}

This abstract is available from: http://www.annals-general-psychiatry.com/content/7/SI/S4 I

(c) 2008 Hoschl; licensee BioMed Central Ltd.

The diagnostic distinction of bipolar affective disorder and schizophrenia in current classification systems ICD10 and DSM IV is based on Kraepelin's definition of "dementia praecox" and "maniodepressive psychosis". However, the validity of the diagnostic distinction is challanged by an accumulating amount of various independent findings. The authors review the similarities and distinctins between both disorders in a range from psychopathology to neuroimaging methods with an emphasis on genetic findings as a major source of evidence of an overlap between bipolar disorder and schizophrenia.

Both bipolar disorder and schizophrenia demonstrate several similar psychopathological and epidemiologic characteristics. Both disorders are strongly influenced by genetic factors, e.g., results of linkage studies show a partial overlap of susceptibility loci. Two relatively common chromosomal aberations are associated with both bipolar disorder and schizophrenia. Association studies of candidate genes in either disorder identified several genes apparently involved in both disorders, such as NRG1, DISC1, and G72/G30. Emerging gene functions possibly involved in both schizophrenia and bipolar disorder include neurogenesis, synaptogenesis, myelinization, and neurotransmition. Bipolar disorder and schizophrenia also demonstrate some similarities in neurotransmitter dysfunction and share some, but not all, pharmacological mechanisms. Cognitive impairment in schizophrenia is well established during acute episodes as well as during remission and is more obvious compared to bipolar disorder. Moreover, children who developed schizophrenia in adulthood are characterised by cognitive, social, emotional, and behavioral impairments, in contrast to an impairment of a lesser degree found in children who later developed bipolar disorder. Also, patients with schizo- phrenia have more extensive structural brain abnormalities than those with bipolar disorder. 